\title{
STRATEGI PENGEMBANGAN MANDIRI ENERGI DAN PUPUK ORGANIK DI DUKUH RUBIYAH DESA BAGENG KECAMATAN GEMBONG KABUPATEN PATI
}

\section{MANAGEMENT STRATEGIES OF SELF-RELIANT ENERGY AND ORGANIC FERTILIZER IN RUBIYAH SUBVILLAGE BAGENG VILLAGE GEMBONG SUBDISTRICT PATI REGENCY}

\author{
Hermain Teguh Prayitno \\ Kantor Penelitian dan Pengembangan Kabupaten Pati \\ Email : hermain_prayitno@yahoo.com
}

\begin{abstract}
Rubiyah sub village has the potential to be developed becoming a self-sufficient energy and fertilizer sub village. It is because the topography of Rubiyah sub village is composed of mountains and the sub village close to rivers which makes a lot of people working in the cattle husbandry sector. The purpose of the study is to formulate strategies in developing Rubiyah sub village becoming a self-sufficient energy and fertilizer sub village. This research uses a descriptive quantitative method. The primary data are obtained by interviewing breeders and owners of biogas installation and organic fertilizer in Rubiyah sub village, Bageng Village Pati Regency. While secondary data are derived from relevant reports and publications. The sampling method is a purposive sampling. The data are analysed by SWOT analysis. The result shows that internal external matrix is located in a position of growth concentration through horizontal integration. The main strategies are: 1) to rebuild and to increase the number of biogas digester by involving the local community as the masons; 2) to increase the production of organic fertilizer. Other strategies are the establishment of market and supporting organizations.
\end{abstract}

Keywords: cattle husbandry, organic fertilizer, self-sufficient energy, strategic management

\begin{abstract}
ABSTRAK
Dukuh Rubiyah memiliki potensi untuk dikembangkan menjadi dukuh mandiri energi dan pupuk organik. Hal ini karena topografi Dukuh Rubiyah yang berupa pegunungan dan dekat dengan sungai menjadikan masyarakatnya banyak yang berprofesi sebagai beternak sapi. Tujuan penelitian ini adalah untuk merumuskan strategi dalam pengembangan mandiri energi dan pupuk organik di Dukuh Rubiyah Desa Bageng. Penelitian ini menggunakan metode deskriptif kuantitatif. Data primer berasal dari hasil wawancara dengan peternak dan pemilik instalasi biogas dan pupuk organik. Sedangkan data sekunder berasal dari penelitian dan dokumen yang relevan. Metode pengambilan sampel responden adalah purposive sampling. Lokasi penelitian di Dukuh Rubiyah Desa Bageng Kecamatan Gembong Kabupaten Pati. Analisis data menggunakan SWOT. Hasil penelitian adalah matriks internal eksternal berada pada posisi pertumbuhan (Growth) konsentrasi melalui integrasi horisontal, sedangkan strategi utama yaitu berupa pembangunan kembali dan memperbanyak bangunan biogas dan pupuk organik dengan melibatkan masyarakat sendiri sebagai perakitnya. Strategi lain yaitu pembangunan pasar dan pendirian organisasi penunjang.
\end{abstract}

Kata kunci: mandiri energi, pupuk organik, strategi pengembangan, ternak sapi 


\section{PENDAHULUAN}

Penelitian mengenai energi dan pupuk organik telah banyak dilakukan, dicoba, dan diaplikasikan oleh pemerintah mulai tahun 2010 hingga tahun 2014 pada kegiatan pengembangan pupuk organik dan biogas (Permentan No 19 Tahun 2010). Namun belum mampu menarik minat masyarakat untuk mencoba dan mengaplikasikannya. Kondisi ini pernah diteliti oleh Hermain (2014), yang menyatakan bahwa strategi pemanfaatan kotoran sapi sebagai bahan baku pengembangan pupuk organik dan biogas adalah sebagai berikut: 1) Memperbanyak produksi biogas, pupuk organik cair dan pupuk organik padat dengan cara mengajak peran serta peternak kecil yang letaknya tersebar di wilayah Kabupaten Pati, serta menggunakan sendiri produk pupuk organik tersebut, serta menawarkannya pada petani terdekat sebagai pengganti pupuk organik kimia; 2) Pemerintah, swasta, dan masyarakat bersama-sama untuk selalu mencari inovasi kesempurnaan proses, peralatan berbahan murah dan berbentuk kecil sehingga mudah diaplikasikan dan dicontoh; 3) Dukungan pemerintah berupa bimbingan dan dana pengadaan peralatan serta dukungan pemberian insentif perlu diberikan kepada pengguna biogas dan pupuk organik.

Hermain (2015) dalam penelitiannya mengenai pemetaan potensi biogas dan pupuk organik menyebutkan bahwa perlu dikembangkan wisata Jeruk Pamelo serta wisata mandiri energi dan pupuk organik. Salah satu dukuh yang memiliki potensi untuk dikembangkan sebagai dukuh mandiri energi dan pupuk organik organic adalah Dukuh Rubiyah di Desa Bageng Kecamatan Gembong Kabupaten Pati. Hal ini berdasarkan pertimbangan bahwa Dukuh Rubiyah memiliki topografi berupa pegunungan dan dekat dengan sungai sehingga sebagian besar masyarakatnya berprofesi sebagai peternak sapi. Berdasarkan latar belakang tersebut, maka tujuan penelitian ini adalah untuk merumuskan strategi dalam pengembangan mandiri energi dan pupuk organik di dukuh Rubiah Desa Bageng Kecamatan Gembong Kabupaten Pati.

\section{TINJAUAN PUSTAKA}

Berdasarkan Undang-undang No 30 Tahun 2007, energi adalah kemampuan untuk melakukan kerja yang dapat berupa panas, cahaya, mekanika, kimia, dan elektromagnetika. Sumber energi adalah sesuatu yang dapat menghasilkan energi, baik secara langsung maupun melalui proses konversi atau transformasi. Pada Pasal 3 Undang-undang tersebut juga dijelaskan mengenai tujuan pengelolaan energi dalam rangka mendukung pembangunan nasional secara berkelanjutan dan meningkatkan ketahanan energi nasional. Adapun tujuan pengelolaan energi adalah: 1) Tercapainya kemandirian pengelolaan energi; 2) Terjaminnya ketersediaan energi dalam negeri, baik dari sumber di dalam negeri maupun di luar negeri; 3) Tersedianya sumber energi dari dalam negeri dan/atau luar negeri sebagaimana dimaksud pada huruf $b$ untuk: a) Pemenuhan kebutuhan energi dalam negeri; b) Pemenuhan kebutuhan bahan baku industri dalam negeri; dan c) Peningkatan devisa negara; 4) Terjaminnya pengelolaan sumber daya energi secara optimal, terpadu, dan berkelanjutan; 5) Termanfaatkannya energi secara efisien di semua sektor; 6) Tercapainya peningkatan akses masyarakat yang tidak mampu dan/atau yang tinggal di daerah terpencil terhadap energi untuk mewujudkan kesejahteraan dan kemakmuran rakyat secara adil dan merata dengan cara: a) Menyediakan bantuan untuk meningkatkan ketersediaan energi kepada masyarakat tidak mampu; 
b) Pembangun infrastruktur energi untuk daerah belum berkembang sehingga dapat mengurangi disparitas antar daerah. 7) Tercapainya pengembangan kemampuan industri energi dan jasa energi dalam negeri agar mandiri dan meningkatkan profesionalisme sumber daya manusia; 8) Terciptanya lapangan kerja; dan 9) Terjaganya kelestarian fungsi lingkungan hidup.

Peraturan Pemerintah No 79 Tahun 2014 menyebutkan bahwa kemandirian energi adalah terjaminnya ketersediaan energi dengan memanfaatkan semaksimal mungkin potensi dari sumber dalam negeri. Kemandirian energi akan dapat dicapai jika 3 (tiga) kriteria utama terpenuhi: 1) Aksesbilitas, yaitu kemampuan untuk mendapatkan akses energi. Hal ini terkait dengan ketersediaan infrastruktur; 2) Daya beli masyarakat terhadap energi; dan 3) Ketersediaan energi (Menteri ESDM, 2016).

\section{METODE PENELITIAN}

Penelitian ini menggunakan metode deskriptif kuantitatif. Data yang digunakan adalah data primer berasal dari wawancara dengan peternak dan pemilik instalasi biogas dan pupuk organik. Sedangkan data sekunder berasal dari dokumen yang relevan. Metode yang digunakan dalam pengambilan sampel responden adalah purposive sampling. Lokasi penelitian di Dukuh Rubiyah Desa Bageng Kecamatan Gembong Kabupaten
Pati. Analisis data menggunakan SWOT untuk merumuskan alternatif strategi (Rangkuti, 1999).

\section{HASIL DAN PEMBAHASAN}

\section{Faktor Strategis Internal Dan Eksternal}

Hasil skoring faktor internal dibuat dalam matriks Evaluasi Faktor Internal (IFE) disajikan pada Tabel 1.

Faktor internal kekuatan dalam pengembangan mandiri energi dan pupuk organik di Dukuh Rubiyah Desa Bageng lebih besar dibandingkan faktor internal "kelemahan" yaitu 2,00 dibanding 0,70. Hal ini menunjukkan bahwa "kekuatan" yang dimiliki Dukuh Rubiyah dalam pengembangan mandiri energi dan pupuk organik mampu mengatasi kelemahan. Kekuatan dominan yaitu melimpahnya kotoran sapi bahkan sebagian kotoran sapi tersebut dibuang; barang dan peralatan reaktor biogas kecil, mudah diperoleh dan murah; serta tersedianya bahan baku energi dan pupuk organik dari kotoran sapi. Dengan demikian Dukuh Rubiyah memiliki jumlah skor yang besar yaitu 0,4 . Hal ini diperkuat dengan kondisi bahwa di Dukuh rubiyah hampir semuanya memiliki ternak sapi dengan perbandingan rumah : kandang yaitu $5: 4$. Sedangkan untuk pembelian bahan praktik berupa tandon air dan konektornya yang berupa pipa peralon dari 2/3 hingga 3 inch dapat diperoleh dari pasaran. 
Tabel 1.

Matrik Internal Faktor Evaluasi (IFE)

\begin{tabular}{|c|c|c|c|c|c|}
\hline \multicolumn{2}{|c|}{ FAKTOR-FAKTOR EKSTERNAL } & Rating & Bobot & Skor & KOMENTAR \\
\hline & \multicolumn{5}{|l|}{ Peluang } \\
\hline S1 & $\begin{array}{l}\text { Kotoran sapi berlimpah dan } \\
\text { sebagian dibuang }\end{array}$ & 4 & 0,10 & 0,40 & $\begin{array}{l}\text { Situasi permukiman jumlah } 5 \\
\text { rumah dan } 4 \text { kandang }\end{array}$ \\
\hline $\mathrm{S} 2$ & $\begin{array}{l}\text { Terujinya teknologi reaktor } \\
\text { kecil } 3300 \text { liter dan } 1100 \text { liter } \\
\text { untuk biogas } 3 \mathrm{KK} \text { dan } \\
\text { produksi pupuk organik } 2 \text { unit }\end{array}$ & 3 & 0,10 & 0,30 & $\begin{array}{l}\text { Dirakit tanggal } 21 \text { Maret } 2016 \\
\text { dan menyala } 1 \text { kompor } \\
\text { tanggal } 28 \text { Maret } 2016 \text { di RT } \\
9\end{array}$ \\
\hline S3 & $\begin{array}{l}\text { Perakitan intalasi biogas dan } \\
\text { pupuk organik dapat dilakukan } \\
\text { sendiri }\end{array}$ & 3 & 0,10 & 0,30 & $\begin{array}{l}\text { RT } 7 \text { dan RT } 9 \text { merakit sendiri } \\
\text { tapi masih diawasi dan } \\
\text { dipandu ahli }\end{array}$ \\
\hline S4 & $\begin{array}{l}\text { Barang dan peralatan reaktor } \\
\text { biogas kecil mudah diperoleh } \\
\text { dan murah }\end{array}$ & 4 & 0,10 & 0,40 & $\begin{array}{l}\text { Tersedia di pasaran (tandon } \\
\text { air, aksesoris sambungan } 1 / 2 \\
\text { s/d } 3 \text { inch) }\end{array}$ \\
\hline S5 & $\begin{array}{l}\text { Kemampuan pengelolaan } \\
\text { instalasi baik }\end{array}$ & 3 & 0,06 & 0,18 & $\begin{array}{l}\text { Terlatih dan komitmen } \\
\text { bersama }\end{array}$ \\
\hline S6 & $\begin{array}{l}\text { Pengguna biogas berada di } \\
\text { sekitar instalasi }\end{array}$ & 3 & 0,07 & 0,21 & $\begin{array}{l}\text { Karena penduduk padat } \\
\text { sehingga jarak antar rumah } \\
\text { dekat }\end{array}$ \\
\hline S7 & $\begin{array}{l}\text { Pengguna pupuk organik } \\
\text { berada di sekitar instalasi }\end{array}$ & 3 & 0,07 & 0,21 & $\begin{array}{l}\text { Sebagian pengguna } \\
\text { mempunyai kebun yang } \\
\text { lokasinya jauh dari rumah }\end{array}$ \\
\hline
\end{tabular}

Kelemahan

W1 LPG murah subsidi pemerintah

$2 \quad 0,1$

0,20

Jika stok habis, harga LPG mahal sehingga masyarakat pakai kayu

W2 Pupuk organik kimia murah di

$1 \quad 0,1 \quad 0,10$

Pemupukan dengan pupuk subsidi pemerintah organik kimia menghasilkan rasa pahit pada jeruk

W3 Investasi teknologi biogas

$2 \quad 0,1 \quad 0,20$

Harga reaktor terjangkau mahal

W4 Dukungan pemerintah rendah

$2 \quad 0,1 \quad 0,20$

Dana yang tersedia dari pemerintah kecil

\begin{tabular}{ccc}
\hline Total kelemahan & 0,70 \\
\hline & 1 & 2,7 \\
\hline
\end{tabular}

Sumber: Pengolahan Data (2016)

Kelemahan yang dominan adalah LPG murah subsidi pemerintah, investasi teknologi biogas mahal, dan dukungan pemerintah rendah. LPG bersubsidi menjadi salah satu kelemahan dalam pengembangan kemandirian energi karena masyarakat akan cenderung memilih menggunakan sumber energi yang siap pakai dibandingkan membuat sumber energi sendiri yang tentunya dinilai kurang praktis. Kelemahan lain adalah penerapan teknologi biogas yang 
membutuhkan pembiayaan yang besar (mahal). Aplikasi teknologi biogas yang dikembangkan selama ini masih dalam bentuk skala besar sehingga jika diterapkan dalam lingkup rumah tangga akan memberikan beban tambahan bagi kondisi perekonomian rumah tangga. Selain itu, dukungan pemerintah dirasa kurang, terutama untuk pengembangan teknologi biogas skala rumah tangga karena program pemerintah untuk penggunaaan teknologi biogas yang selama ini berjalan, belum memberikan solusi untuk skala rumah tangga.

Hasil skoring faktor eksternal dibuat dalam matriks Evaluasi Faktor Enternal (EFE) disajikan Tabel 2.

Tabel 2.

Matrik Eksternal Faktor Evaluasi (EFE)

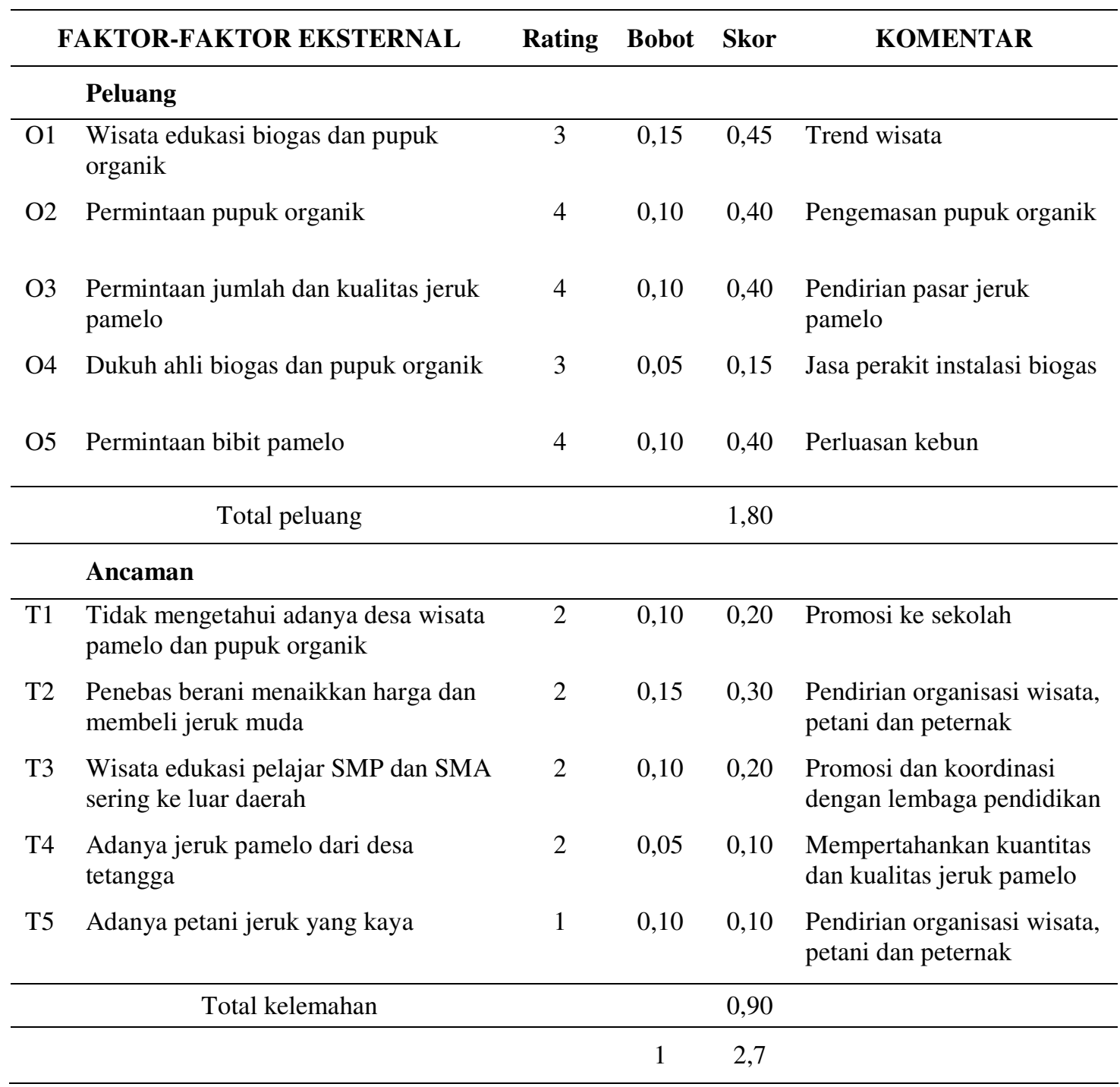

Sumber: Pengolahan Data (2016) 
Faktor eksternal "peluang” Dukuh Rubiyah menjadi dukuh mandiri energi dan pupuk organik lebih besar dibandingkan faktor eksternal "ancaman" yaitu 1,80 dibanding 0,90. Hal ini menunjukkan bahwa peluang yang dimiliki Dukuh Rubiyah mampu mengatasi ancaman. Peluang dominan yaitu wisata edukasi biogas dan pupuk organik. Hal ini menjadi peluang karena Dukuh Rubiyah merupakan wilayah Desa Bageng Kecamatan Gembong yang telah menetapkan diri sebagai Desa Wisata Pamelo. Namun, peluang ini masih harus dikembangkan karena sejauh ini wisata Jeruk Pamelo belum menunjukkan bukti nyata kepada masyarakat, baik dari segi peningkatan penghasilan dari penjualan Jeruk Pamelo maupun dari penjualan ternak sapi itu sendiri. Belum adanya keuntungan yang diperoleh dari peluang disebabkan oleh masih banyaknya faktor eksternal seperti adanya tengkulak, penebas, dan atau calo pedagang sapi. Belum adanya pasar Jeruk Pamelo, sapi, bibit jeruk, menyebabkan taraf ekonomi masyarakat belum meningkat. Ini sejalan dengan ancaman dominan yaitu penebas berani menaikkan harga dan membeli jeruk muda. Total Skor IFE $(2,70)=\mathrm{EFE}$ $(2,70)$ menunjukkan faktor internal dan eksternal memberikan pengaruh yang sama besar terhadap pengembangan kemandirian energi dan pupuk organik di Dukuh Rubiyah. Matriks Internal Eksternal pengembangan Dukuh Rubiyah menjadi dukuh mandiri energi dan pupuk organik disajikan pada Gambar 1.

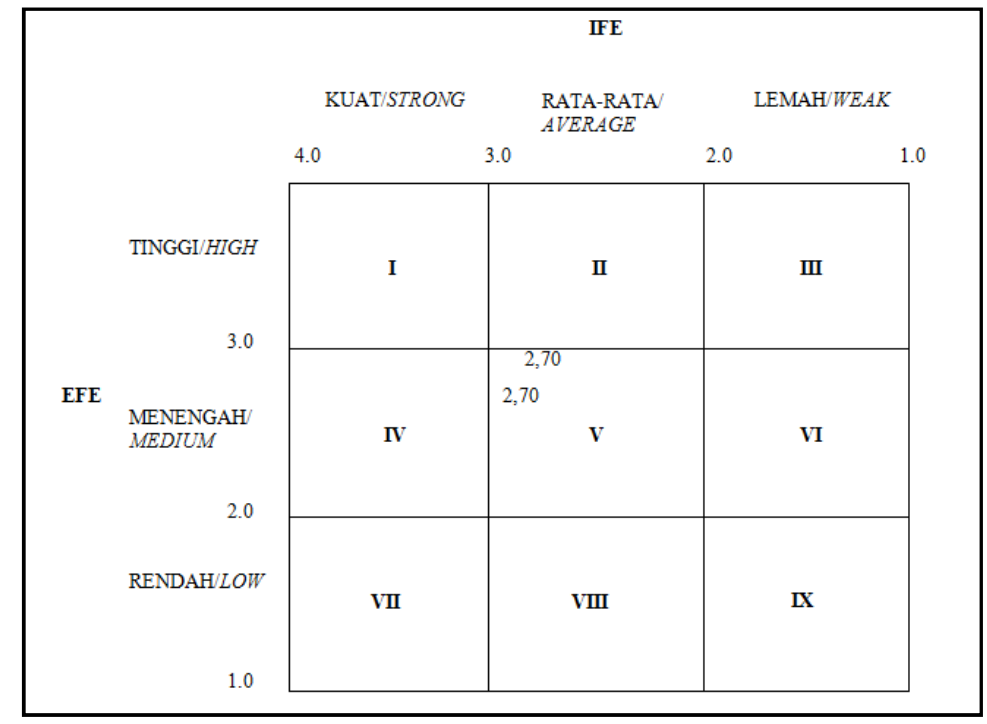

Gambar 1.

Matriks Internal Eksternal Pengembangan

Kemandirian Energi dan Pupuk organik Dukuh Rubiyah

Sumber: Pengolahan Data (2016)

Faktor internal dan eksternal berada pada sel $\mathrm{V}$ yaitu medium growth melalui integrasi horizontal (Rangkuti, 1999). Secara terperinci alternatif strategi disajikan pada Tabel 3. Sesuai dengan pertumbuhan (Growth) konsentrasi melalui integrasi horisontal dengan cara membangun perusahaan di tempat lain, 
dan dalam hal ini adalah penambahan pembuatan instalasi biogas dan pupuk organik di semua penghasil kotoran sapi di Dukuh Rubiyah baik mandiri maupun kerjasama dengan Pemda, dan memanfaatkan lahan untuk instalasi biogas, pupuk organik, produk Jeruk Pamelo, bibit Jeruk Pamelo untuk wisata.

Disamping memperbanyak produsen biogas dan pupuk organik maka dikembangkan juga pasarnya yaitu upaya pembangunan pasar pupuk organik padat, Jeruk Pamelo, sapi potong, dan bibit pamelo. Menciptakan jenis jasa melalui pembentukan organisasi (akta notaris) wisata pamelo dan mandiri energi dan pupuk organik dan berkoordinasi dengan lembaga pendidikan dan pemerintah untuk wisata dan kelancaran bantuan, dan kemampuan membangun.

\section{Tabel 3.}

Matriks Alternatif Strategi

\begin{tabular}{|c|c|}
\hline $\begin{array}{l}\text { SWOT IFAS (2,7) EFAS }(2,7) \\
\text { Growth konsentrasi melalui integrasi horizontal } \\
\text { dan Stability (tak ada perubahan profit } \\
\text { sekarang) } \\
\text { 1. Membangun perusahaan di tempat lain } \\
\text { 2. Meningkatkan jenis produk } \\
\text { 3. Penciptaan jenis jasa yang melengkapi } \\
\text { perusahaan }\end{array}$ & $\begin{array}{l}\text { S-W }(\mathbf{2 , 7}) \text { Medium Integrasi horisontal } \\
\text { 1. Pembuatan intalasi baru yang dibangun } \\
\text { sendiri di seluruh lokasi bahan baku } \\
\text { 2. Memanfaatkan lahan kosong yang tidak } \\
\text { memiliki ternak } \\
\text { 3. Mengemas dan menjual pupuk organik } \\
\text { yang dihasilkan } \\
\text { 4. Membuat organisasi kelompok mandiri } \\
\text { energi dan pupuk organik } \\
\text { 5. Meyakinkan pemerintah mengenai } \\
\text { teknologi murah, mudah tepat guna, dan } \\
\text { mengajukan bantuan kerjasama } \\
\text { 6. Mengajak, melatih cara perakitan instalasi } \\
\text { biogas dan pupuk organik di lingkungan } \\
\text { sendiri }\end{array}$ \\
\hline 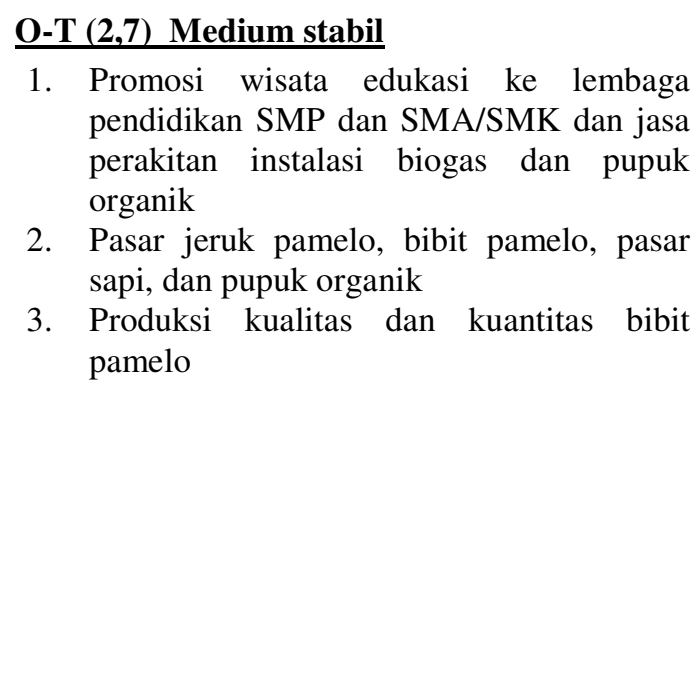 & $\begin{array}{l}\text { SW-OT } \\
\text { 1. Pembanguan lagi instalasi biogas dan } \\
\text { pupuk organik di semua penghasil kotoran } \\
\text { sapi di Dukuh Rubiyah baik mandiri } \\
\text { maupun kerjasama dengan Pemerintah } \\
\text { Daerah } \\
\text { 2. Pemanfaatan lahan untuk instalasi biogas, } \\
\text { pupuk organik, produk jeruk pamelo, bibit } \\
\text { jeruk pamelo untuk wisata } \\
\text { 3. Pembangunan pasar pupuk organik padat, } \\
\text { jeruk pamelo, sapi potong, dan bibit } \\
\text { pamelo } \\
\text { Membuat organisasi (akta notaris) wisata } \\
\text { pamelo dan mandiri energi dan pupuk } \\
\text { organik dan berkoordinasi dengan lembaga } \\
\text { pendidikan dan pemerintah untuk wisata } \\
\text { dan kelancaran bantuan. }\end{array}$ \\
\hline
\end{tabular}

Sumber: Pengolahan Data (2016) 


\section{KESIMPULAN DAN SARAN}

\section{Kesimpulan}

Matriks internal eksternal pengembangan Dukuh Rubiyah menjadi dukuh mandiri energi dan pupuk organik berada pada posisi pertumbuhan (Growth) konsentrasi melalui integrasi horisontal. Pembangunan kembali dan memperbanyak bangunan biogas dan pupuk organik dengan melibatkan masyarakat sendiri sebagi perakitnya, menjadi strategi utama disamping pembangunan pasar dan pendirian organisasi penunjang.

\section{Saran}

1. Pemberdayaan masyarakat mandiri energi dan pupuk organik di Dukuh Rubiyah

2. Menggunakan sendiri energi dan pupuk organik untuk peningkatan ekonomi

3. Pembangunan pasar wisata Jeruk Pamelo, pasar sapi potong, dan pasar pupuk organik.

\section{DAFTAR PUSTAKA}

Badan Pusat Statistik Kabupaten Pati,. 2013. Pati Dalam Angka Tahun 2012. Pati: BPS Kabupaten Pati.

Menteri Energi dan Sumber Daya Mineral Republik Indonesia. 2016.

Mampukah Sektor Migas Berkontribusi Menuju

Kemandirian Energi Nasional. http://esdm.go.id/berita/40-

migas/2449-tiga-faktor-

kemandirian-energi-nasional.pdf, diakses tanggal 6 April 2016.

Peraturan Pemerintah Republik Indonesia Nomor 79 Tahun 2014 tentang Kebijakan Energi Nasional.

Peraturan Menteri Pertanian Nomor 19/Permentan/Ot.140/2/2010 tentang Pedoman Umum Program Swasembada Daging Sapi.

Prayitno, H. T. 2014. Strategi Pemanfaatan Kotoran Sapi. Jurnal litbang X (1): 43-51.

Prayitno, H. T. 2015. Pemetaan Potensi Biogas dan Pupuk organik Dari Kotoran Sapi Untuk Mendukung Wisata Pamelo di Desa Bageng Kecamatan Gembong Kabupaten Pati. Jurnal Litbang XI (2): 103112.

Rangkuti, F. 1999. Analisis SWOT Teknik Membedah Kasus Bisnis. Jakarta: PT Gramedia Pustaka Utama.

Undang-Undang Republik Indonesia Nomor 30 Tahun 2007 tentang Energi.

\section{BIODATA PENULIS}

Hermain Teguh Prayitno, lahir 11 April 1970 di kota Rembang Jawa Tengah. Magister Ilmu Lingkungan dari Universitas Diponegoro (UNDIP) Semarang tahun 2008. Saat ini bekerja sebagai peneliti muda di Kantor Penelitian dan Pengembangan Kabupaten Pati. 